\title{
Gebelik ve Postpartum Dönemde Kadın Ruh Sağlığı: Derleme
}

\section{Çalışması}

\section{Women's Mental Health in Pregnancy and Postpartum Period: Review Study}

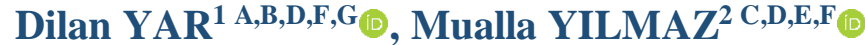 \\ ${ }^{1}$ Mersin Üniversitesi Sosyal Bilimler Enstitüsü Kadın Araştırmaları Ana Bilim Dalı, Mersin, Türkiye \\ ${ }^{2}$ Mersin Üniversitesi Hemşirelik Fakültesi Ruh Sağlı̆̆ı ve Hastalıkları Hemşireliği Ana Bilim Dalı, Mersin, Türkiye
}

ÖZ

\begin{abstract}
Kadınlar gebelik ve doğum sonrası dönemde yoğun fizyolojik, psikolojik ve sosyal değişimler yaşamaktadır. Biyolojik ve çevresel faktörlerin etkisiyle gebelik ve doğum sonrası dönem bazı kadınlar için zor bir süreç haline gelebilmektedir. Gebelik ve doğum sonrası dönem psikiyatrik hastalıkların ortaya çıktığı ya da nüks ettiği karmaşık bir süreç olabilmektedir. Bu dönemde ortaya çıkan psikiyatrik bozukluklar göz ardı edilebilmektedir. Ancak gebelik ve doğum sonrası dönemde ruhsal hastalıkların teşhis ve tedavisi oldukça önemlidir. Çünkü gebelik ve doğum sonrası süreçte annenin ruh sağlığı bebeği de etkilemektedir. Bu derlemenin amacı gebelik ve doğum sonrası dönemde sık karşılaşılan psikiyatrik bozukluklar konusunda literatür bilgisini gözden geçirmek ve müdahale yöntemleri hakkında önerilerde bulunmaktır.
\end{abstract}

Anahtar Kelimeler: Gebelik, Postpartum, Ruh Sağlı̆̆ı.

\section{ABSTRACT}

Women experience intensive physiological, psychological and social changes during pregnancy and postpartum period. Due to the effects of biological and enviromental factors, pregnancy and postpartum period could be a difficult process for some of them. Pregnancy and postpartum period might be complicated processes in which psychiatric diseases occur or relapse. Psychiatric disorders that occurs in that period could be ignored. However, early diagnosis and treatment of mental illnesses is quite significant because mothers` mental health affects babies during pregnancy and postpartum period. The aim of this composition is to revise the literature on the psychiatric disorders that are often seen during the pregnancy and postpartum period and to provide suggestions as to the treatment methods.

Key Words: Pregnancy, Postpartum, Mental Health.

\section{GíRiș}

Kadın ruh sağlığı alanı üzerine artan ilgi, yaşam koşullarının iyileştirilmesi ve yeni ilaçların geliştirilmesi gibi umut verici gelişmelere rağmen cinsiyet, 1rk, etnik köken ve sosyoekonomik duruma dayalı eşitsizlikler devam etmektedir. $\mathrm{Bu}$ sebeple kadınlar ruhsal bozukluklar açısından erkeklere kıyasla yüksek risk altındadır (1).

Kadınların psikiyatrik bozukluk geliştirme riski doğurganlık çağında artmaktadır. Hamilelik ve doğum sonrası dönem psikiyatrik rahatsılıkların ortaya çıktığı ya da yeniden alevlendiği riskli bir dönemi temsil eder. Bu nedenle birçok kadın hamilelik ve doğum sonrası dönemde psikiyatrik tedaviye ihtiyaç duymaktadır (2). 
Annenin hamilelik sürecinde yaşadığı ruhsal sorunların fetüsü etkilediği, anne-bebek arasındaki bağlanma ilişkisini bozduğu ve doğum sonrası dönemde annenin var olan kapasitesinden ödün vererek bakım verme isteğine zarar verdiğine yönelik güçlü bir kanı bulunmaktadır. Dahası kadınların çocuk yetiştirme üzerine olan duygu durum bozuklukları, partnerleriyle olan ilişkilerinde de sorun yaratmakta ve evlilik tatmininde düşüşe neden olmaktadir (3).

$\mathrm{Bu}$ derlemenin amacı gebelik ve gebelik sonrası dönemde sık karşılaşılan psikiyatrik bozukluklar konusunda literatür bilgisini gözden geçirmek ve müdahale yöntemleri hakkında önerilerde bulunmaktır.

\section{Gebelikte Depresyon}

Gebelik ve doğum üretken çağdaki bir kadının doğal yaşam döngüsünün bir parçasıdır. Kadınlar gebelik ve doğum sürecinde yoğun fizyolojik, psikolojik ve sosyal değişimler yaşamaktadır. Gebeliğin ruhsal bozukluklar açısından koruyucu bir dönem olduğuna ilişkin düşünce artık terk edilmiştir (4). Çünkü gebelik mutluluk verici bir süreç olabileceği gibi anne adayını endişe ve karamsarlığa da sürükleyebilir. Gebelik ve sonrasındaki süreçte gelişebilen en önemli sağlık sorunlarından birinin depresyon olabileceği unutulmamalıdır (5).

Depresyon tüm dünyada yaygın olarak görülen ve bireyin işlevselliğini önemli ölçüde etkileyen bir ruhsal bozukluktur. Depresyon en fazla doğurganlık çağındaki kadınlarda görülmekle birlikte gebelikte görülme sıklığ1 artış göstermektedir (6). DSM- 5`e göre majör depresif bozukluğun tanımlanması için en az iki haftalık süre içerisinde 5 veya üzeri belirtinin bulunması gerekmektedir. Bu belirtiler; çok veya az uyuma, ağırlık kaybı ya da iştahta değişme, enerjinin kaybedilmesi, değersiz ya da suçlu hissetme, odaklanma, düşünme ya da karar alma güçlüğü, psikodevinimsel yavaşlama ya da yerinde duramama ile yineleyen ölüm ya da öz kıyım düşünceleridir. Belirtiler önemli bir kayba karşı verilen normal tepkiden farklıdır ve şiddetlidir. Belirtilerin yanı sıra üzüntülü duygu durumu ya da her zamanki etkinliklere ilgi ve zevk kaybinın bulunması gerekmektedir (7).

Gebelik döneminde depresyon göz ardı edilebilmektedir. Uyku bozukluğu, iştah ve enerji kaybı gibi semptomlar ruh halindeki değişikliklerden ziyade hamileliğin somatik deneyimlerine bağlanabilmektedir (8). Ancak anne adayı ile yapılacak dikkatli gözlem ve görüşmelerde umutsuzluk, hayattan zevk alamama, suçluluk duyguları ile intihar düşüncelerinin varlığının saptanması depresyon tanısının konulmasina yardımcı olur (9).

Ülkemizde Cebeci ve ark. (2002) yaptıkları çalışmada 100 kadın katılımcının $12{ }^{`}$ sinde yüksek depresyon (17 ve üzeri) semptomu saptamıştır (10). Gebelikte depresif belirti görülme sıklığını Karaçam ve Ançel (2007) \%27.9; Arslan ve ark. (2011) \%35 olarak bulgulamışlardır $(11,12)$.

Düşük ya da ölü doğum öyküsü, hamilelik konusunda ikilem, kişisel ya da ailesel depresyon öyküsü, yaşayan çocuk sayısı, genç yaşta gebelik ve sosyoekonomik düzeyi düşük

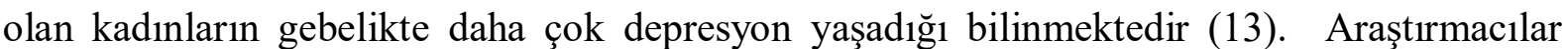
yüksek nörotisizm, düşük benlik saygısı, kendini aşırı eleştirme, düşük dışa dönüklük ve bağımlı olma gibi özellikler ile depresyon arasında anlamlı ilişki olduğunu bulgulamaktadır (14). Ayrıca doğum öncesi anksiyete, negatif bilişsel stil, önemli yaşamsal olaylar, düşük sosyal 
destek, geçmişte kötüye kullanım öyküsünün olması da depresyonun önemli yordayıcılarıdır (15).

Gebelikte görülen depresyon hem fetüsü hem de anneyi olumsuz etkiler. Gebelikte depresyon düşük doğum ağırlıklı bebek doğurmaya, fetal ölüme, erken doğuma ya da bebeğin anne karnında gelişim geriliğine neden olabilmektedir (16). Gebelik döneminde depresyon postpartum döneminde devam edebilmektedir (17). Bu sebeple gebelik döneminde depresyonun etkili tedavisi postpartum depresyonun önlenmesine yönelik önemli bir adım olacaktır (18).

Gebelik dönemi depresyonunun tedavisi için farmakolojik ve farmakolojik olmayan çeşitli tedavi seçenekleri mevcuttur. Psikoterapi, kişilerarası psikoterapi, bilişsel davranışçı terapi ve elektrokonvülsif tedavi (EKT) farmakolojik olmayan seçeneklerdir. Trisiklik antidepresanlar ve serotonin geri alım inhibitörleri ise depresyonun farmakolojik tedavisinde kullanılmaktadır (2).

\section{Annelik Hüznü}

Annelik hüznü yeni doğum yapmış kadınların \%50- \%85 inin deneyimlediği yaygın bir durumdur. Stres, endişe, ağlama, sinirlilik, konsantrasyon güçlüğü, huzursuzluk, incinebilirlik gibi durumlarla karakterizedir. Annelik hüznü bebeğin doğumundan sonraki ilk hafta ortaya çıkmakta ve belirtiler genellikle iki hafta içerisinde tedavi gerektirmeksizin yok olmaktadır.

Annelik hüznü sanılanın aksine doğumda hangi yöntemin kullanıldığı (sezaryen- normal doğum) ya da annenin doğum sayısı gibi durumlardan bağımsız görülmektedir (19). Annelik hüznünde doğum sonrası hormonal dengede ortaya çıkan ani değişikliklerin ya da oksitosin kaynaklı biyolojik sistemin aktifleşmesinin etkili olduğu düşünülmektedir (20).

Doğum öncesi dönemdeki anksiyete ve depresyon doğum sonrası dönemde annelik hüznü ve postpartum depresyon açısından risk oluşturmaktadır (21). Annelik hüznü olan kadınların öykülerinde premenstrual gerginlik, doğum korkusu ve sosyal uyum güçlüğü sıktır. Ayrıca gebeliğin üçüncü trimesterinde anksiyete ve depresif semptomlar yaşamışlardır (22). Annenin evlenmeden önce gebe kalması, bebeğin babasının yeterli ilgi ve desteği göstermemesi, anne adayının ailesi ile evlilik ve çocuk bakımı konusunda çatışma içerisinde olması annelik hüznünün görülmesinde etkili olmaktadır (23).

Annelik hüznü ile baş etme noktasında öncelikle bütün gebe kadınlar annelik hüznüne ilişkin belirtiler konusunda eğitilmelidir. Belirtilerin iki haftadan uzun sürmesi durumunda annenin psikiyatrik destek alması sağlanmalıdır. Özgeçmişinde psikiyatrik bozukluk ve tıbbi hastalık öyküsü bulunan, gebeliği planlı olmayan, sosyal desteği yetersiz olan gebeler doğum sonrası dönemde psikiyatrik açıdan riskli grubu oluşturmaktadır. Doğum öncesi dönemde risk grubunda olan anne adayları belirlenmeli ve diğer aile üyeleri de bilgilendirilerek destek sistemleri harekete geçirilmelidir. Doğum sonrası dönemde yaşanan sorunlara ilişkin çalışmalara doğum öncesi dönemden başlanmalı ve bu çalışmalar doğum sonrası ilk altı aylık dönemi de içine alacak şekilde genişletilmelidir (24). 


\section{Postpartum Depresyon}

Doğumu takip eden ilk 6 ay depresyon için oldukça riskli bir dönemdir. Postpartum depresyonda doğum sonrası dönemde görülen oldukça yaygın, ciddi bir sağlık problemidir. Postpartum depresyon prevalansı \%13-\%19 aralı̆̆ındadır (25).

Postpartum depresyonun patofizyolojisi tam olarak açiklanamasa da biyolojik faktörlerin postpartum depresyon oluşumunda önemli rol oynadığ düşünülmektedir. Gebelik ve doğum sonrası dönemde steroit ve peptit hormonlarındaki hızlı değişimler sebebi ile annenin hipotalamus - hipofiz - adrenal aks ve hipotalamus - hipofiz - gonodal aks1 etkilenmektedir. Endokrin akslarındaki düzensizlik gebelik ve doğum sonrası dönemde annenin duygu durumu üzerinde etkili olmaktadır (26). Gebelik süresince ve doğum sonrasında estrodiol seviyesindeki dalgalanmalar serotonin sistemindeki dengeyi bozarak bu dönemde anneyi depresif semptomlara karşı hassas kılmaktadır (25). Üreme hormonlarındaki dalgalanmaların yanı sıra nörosteroid, nöral disfonksiyon, genetik ve bağışıklık sisteminin de postpartum depresyonla ilişkili olduğu düşünülmektedir (27).

Tiroid bezinin anormal çalışması, klinik olarak tespit edilmeyen tiroid yetmezliği ya da mevcut tiroid antikorları postpartum başlangıçlı depresyon için risk faktörü oluşmaktadır. $\mathrm{Bu}$ bulgulara dayanarak postpartum depresyonda tedavi için başvuran hastalarda tiroid bezinin işleyiş̧i kontrol edilmelidir (28).

Yapılan meta analiz değerlendirmeleri sonucunda postpartum başlangıçlı depresyon için literatürde 13 anlamlı risk faktörü belirlenmiştir. Bunlar; doğum öncesi depresyon, benlik saygısı, çocuk bakımı stresi, doğum öncesi (prenatal) anksiyete, yaşamsal stresler, sosyal destek, medeni durum, depresyon tanısı geçmişi, yeni doğanın mizacı, annelik hüznü, evlilik ilişkisi, istenmeyen /beklenmeyen gebelik ve sosyo-ekonomik durumdur (29).

Konuya ilişkin yapılan araştırmalarda da benzer şekilde antenatal depresyon ve anksiyete, hamilelik öncesi psikiyatrik rahatsızlıklar, zayıf evlilik ilişkisi, stresli yaşam olayları, hamileliğe karşı olumsuz tutum ve sosyal destek azlığ yordayıcılarıdır (30). Geçmişte psikiyatrik tedavi, yüksek anksiyete duyarlılığı, hamilelikte yüksek stres düzeyi, doğum korkusunun aşırı olması, düşük ailesel yeterlilik ve hamilelikte depresyon varlığı postpartum semptomları alevlendirmektedir (31).

Ülkemizde yürütülen bir çalışmada doğum yapan kadınların \%12,5'inde postpartum depresyon görüldüğü bulgulanmıştır. Yaşam şeklinin, aile içi stres faktörlerinin, sorunlu evliliklerin, şiddet görmenin, istenmeyen gebeliğin, ruhsal problemlere sahip olmanın, kötü sosyal ilişkilerin postpartum depresyonu etkilediği görülmüştür (32). Yaş, yaşayan çocuk sayısı, maddi durum, planlı gebelik, emzirme problemleri, eğitim, bebeğin cinsiyeti, geçmiş depresyon deneyiminin ele alındığ 1 bir çalışmada tüm bu risk faktörlerinin içinde postpartum depresyonu en fazla geçmiş depresyon deneyiminin etkilediği bulgulanmıştır (33). 49 anneyle yürütülen başka bir çalışmada doğum öncesi kaygı ve depresyon riski yüksek olan anne adaylarının doğum sonrasında postpartum depresyonu yaşadığı görülmüştür (34). Ayrıca eşin eğitim düzeyinin düşük olmasının yüksek postpartum depresyon riski ile ilişkili olduğu bulgulanmıştır (35).

Tedavi edilmeyen postpartum depresyon anne ve yeni doğanın sağlığını etkiler. Postpartum depresyon anne ve yeni doğan iletişimini, çocuğun gelişimini etkileyen önemli bir sorundur. Annenin yeni doğanla bağ kurma hassasiyeti ve ebeveynlik stili bebeğin bilişsel, 
sosyal ve davranışsal becerilerinin sağlıklı bir şekilde gelişmesi için gereklidir. Ancak depresif anne genellikle daha az bağlanma ve duyarlılık gösterir (26).

Gebelik döneminde anne adayının postpartum depresyonun belirtileri ve etkileri konusunda bilgilendirilmesi gerekir. Annenin postpartum depresyon tanıs1 almasi durumunda çeşitli tedavi seçenekleri bulunmaktadır (36). Postpartum depresyonda psiko-farmokolojik tedavi seçeneğinin anne sütüne bilinen ve bilinmeyen birçok etkisi bulunmaktadır. Gebelik ve emzirme döneminde ağır depresyon durumunda kar zarar hesabı göz önünde bulundurularak ilaç tedavisine başlanması önerilir. Gebelik ve emzirme sırasında en düşük etkin dozda ve mümkünse tek ilaç kullanılmalıdır. Fetüs ya da bebek yakından izlenmelidir (37). Bunun yanı sıra kişiler arası psikoterapi, bilişsel davranışçı terapi, psikodinamik psikoterapi ve diğer destekleyici terapiler yan etkisi olmayan ve belirtileri hafifletici tedavi seçenekleridir (38).

\section{Postpartum Psikoz}

Postpartum psikoz doğumdan sonraki ilk birkaç hafta içerisinde ortaya çıkan ve her 1000 yeni doğum yapan annenin 1-2`sinde görülebilen oldukça ciddi bir ruhsal bozukluktur. Vakaların yarısından fazlası ilk hafta, \%75 inden fazlası ilk 2 hafta içerisinde görülmektedir. Bu bakımdan postpartum psikoz annelik hüznünün görüldüğü dönem ile çakışmaktadır (19).

DSM-5 göre postpartum psikoz "kısa psikotik bozukluk" tanısı kapsamında değerlendirilmektedir. Postpartum psikozda semptomlar doğumdan sonraki ilk 4 hafta içerisinde ortaya çıkmaktadır. Kısa psikotik bozukluk tanısının konulabilmesi için epizodun en az 1 gün ya da 1 aydan az sürmesi gerekmektedir. Hasta 1 ay içerisinde bu hastalığ geliştirir. Sonrasında sanrı, varsanı ve değişik konuşmanın olduğu bir psikoz evresinden tamamen iyileşerek çıkar (39).

Postpartum psikozda annede delüzyon, halüsinasyon, konfüzyon, yemek yememe, uyumama, hızlı duygu durum değişiklikleri görülmektedir. Bu semptomların yanı sıra postpartum psikozunda postpartum depresyonuna ait semptomlarda görülebilmektedir. $\mathrm{Bu}$ noktada psikozun şiddetinin anlaşılabilmesi için postpartum depresyondan tanısal olarak ayrımının yapılması önemlidir (22).

Doğum öncesinde depresyon, annenin bekar olması, ileri yaşta doğum, otoümnin tiroid bozukluğu, geçmişte psikiyatrik bozukluk ve aile geçmişinde affektif psikoz hikayesi olan kadınlarda postpartum psikoz görülme riski artmaktadır (40). Bipolar ve postpartum psikoz tanısı öyküsü olan kadınlarda postpartum psikoz görülme riski yüksektir (4). Beyin görüntüleme tekniklerinin kullanıldığı bir çalışmada superior ve medial temporal bölge ile antrerior cingulatedeki küçülmenin kadınlarda postpartum psikoz epizodu oluşmasına yatkınlaştırıcı bir etkisinin olduğu ve risk altındaki kadınların belirlenmesinde önemli bir bulgu olacağ 1 belirtilmiştir (41).

Postpartum psikozda semptomlar dalgalı ve gizli bir seyir gösterebilmekte ve bu durum psikotik semptomların göz ardı edilmesine neden olmaktadır. Bu nedenle psikozun erken semptomları sorgulanırken hastaya ve ailesine paranoid düşünceler, yoğun suçluluk duyguları, öz kıyım ya da bebeğe zarar verme düşüncelerinin varlığı sorulmalıdır (42). Ailenin iş birliği annenin ve bebeğin güvenliği, annenin desteklenmesi ve annenin psikiyatrik muayeneden geçirilerek tedaviye başlanması açısından oldukça önemlidir (43).

Postpartum psikozu acil psikiyatrik müdahale ve hastaneye yatışı gerektirmektedir. Hastaneye yatışı olmayan kişiler 24 saat boyunca bir yetişkinin gözetiminde bulunmalıdır. 
Postpartum psikozu görülen kadınlar hem kendileri hem bebeklerine zarar verebileceğinden yalnız bırakılmamalı, anne ve bebeğin yüksek düzeyde güvenliği sağlanmalıdır (22). Hastaneye yatışı yapılan anne hakkında gündüz ve gece hemşireler notlarına dikkat etmelidir. Çünkü yeni anne geceleri tuhaf davranışlar sergilerken gündüzleri normal görünebilir ya da tam tersi davranışlar görülebilir. Ancak psikoz her zaman tıbbi bir acil durum olarak değerlendirilir (19).

Postpartum psikozun tedavisinde antipsikotikler, mood stabilizatörleri, hormonterapi, antidepresanlar ve EKT (elektrokonvülsif tedavi) kullanılmaktadır. Yapılan araştırmalar postpartum psikozu önleyici olarak lityum, tedavi edici olarak EKT'yi etkili stratejiler olarak bulgulamıştır (44).

\section{SONUÇ}

Kadınlarda 18-45 yaşları arasındaki reprodüktif dönem multidisipliner bir yaklaşımla ele alınması gereken, kişinin tüm organ sistemini etkileyen biyolojik aynı zamanda psikolojik ve sosyo-kültürel bir zaman dilimidir.

Gebelik ve gebelik sonrası süreç ruhsal hastalıkların ortaya çıkabileceği ya da nüks edebileceği bir dönemdir. Anne adayının ruhsal rahatsızlığının tedavi edilmemesi anne- bebek sağlığ1 ve ilişkisini olumsuz etkiler. $\mathrm{Bu}$ sebeple gebelik ve postpartum dönemde ruhsal hastalıkların erken tanı ve tedavisi oldukça önemlidir.

Perinetal ruh sağlığında risk faktörleri belirlenmeli ve rutin kontroller yapılmalıdır. Geçmişte kişide ya da ailede psikiyatrik bir rahatsızlığın olup olmadığı, fiziksel, cinsel ya da duygusal kötüye kullanım öyküsü, partner şiddeti ve olumsuz yaşam olaylarının varlığına özellikle dikkat edilmelidir. Yeni doğan ve bebek servislerinde görevli sağlık profesyonelleri psikolojik iyilik halini değerlendirecek ve kapsamlı bir psikolojik destek verecek bilgi birikime sahip olmalıdır. Farmakolojik tedavilerin yanı sıra psikoterapi, EKT ve diğer destekleyici tedavilerden faydalanılmalıdır (45).

\section{Çıkar Çatışması}

Yazarlar arasında çıkar çatışması yoktur.

\section{KAYNAKLAR}

1. Schulz, A. J., Mullings, L. (2006). Gender, race, class \& health: International approaches. San Francisco: Jossey-Bass.

2. Hendrick, V. (2006). Psychiatric disorders in pregnancy and the postpartum: Principles and treatment. New Jersey: Humana Press.

3. Levin, B. L., Becker, M. A. (2010). A public health perspective of women's mental health. New York: Springer.

4. Özdamar, Ö., Yılmaz, O., Beyca, H. H., Muhcu, M. (2014). Gebelik ve postpartum dönemde sık görülen ruhsal bozukluklar. Zeynep Kamil Tip Bülteni, 45 (2), 71-77.

5. Marakoğlu, K., Şahsıvar, M. Ş. (2008). Gebelikte depresyon. Türkiye Klinikleri J Med Sci, 28, 525-532.

6. Erbil, N., Oruç, H., Karabulut, A. (2009). Gebelikte depresyon ve etkileyen faktörlerin belirlenmesi. Türkiye Klinikleri J Gynecol Obst., 19 (2), 67-74.

7. Kring, A. M., Johnson, S. L., Davison, G., Neale, J. (2014). Anormal psikolojisi. (M. Şahin, Çev.) Ankara: Nobel Akademik Yayıncılık. 
8. Burt, V. K., Hendrick, V. C. (2005). Clinical manual of women's mental health. Washington: American Psychiatric Publishing.

9. Dağlar, G., Nur, N., Bilgiç, D., Kadığlu, M. (2015). Gebelikte duygulanım bozukluğu. KASHED, 2 (1), 27-40.

10. Cebeci-Altınay, S., Aydemir, Ç., Göka, E. (2002). Puerperal dönemde depresyon semptom prevalansı: obstetrik risk faktörleri, kaygı düzeyi ve sosyal destek ile ilişkisi. Kriz dergisi, 10 (1), 11-18.

11. Karaçam, Z., Ançel, G. (2007). Depression anxiety and influencing factors in pregnancy: a study in a Turkish population. Midwifery, 25, 344-356.

12. Arslan, B., Arslan, A., Kara, S., Öngel, K., Mungan, M.T. (2011). Gebelik anksiyete ve depresyonunda risk faktörleri: 452 olguda değerlendirme. Tepecik Ĕ̈it Hast Derg, 21 (2), 79-84.

13. Melville, J. L., Gavin, A., Guo, Y., Fan, M.Y., Katon, W.J. (2010). Depressive disorders during pregnancy. Obstet Gynecol, 116, 1064-1070.

14. Bunevicius, R., Kusminskas, L., Bunevicius, A., Nadisauskiene, R.J., Jureniene, K., Pop, V.J.M. (2009). Psychosocial risk factors for depression during pregnancy. Acta Obstetricia et Gynecologica, 88, 599-605.

15. Leigh, B., Milgrom, J. (2008). Risk factors for antenatal depression, postnatal depression and parenting stress. BMC Psychlatry, 8 (24), 1-11.

16. Grote, N.K., Bridge, J.A., Gavin, A.R., Melville, J.L., Iyengor, S., Katon, W.J. (2010). A meta-analysis of depression during pregnancy and the risk of preterm birth, low birth weight, and intrauterine growth restriction. American Medical Association, 67 (10), 1012-1024.

17. O`Hara, M. W., Swain, A. M. (1996). Rates and risk of postpartum depression a meta analysis. International Review of Psychiatry, 8 (1), 37-54.

18. Çalık-Yeşilçiçek, K., Aktaş, S.(2011). Gebelikte depresyon: sıklık, risk faktörleri ve tedavisi. Psikiyatride Güncel Yaklaşımlar, 3(1), 142-162.

19. Bennet, S. S. (2007). Postpartum depression for dummies. New Jersey: Wiley Publishing.

20. Öztürk, N., Aydın, N. (2017). Anne ruh sağlığının önemi. Kadın ve Toplumsal Cinsiyet Araştırmaları Dergisi, 2, 29-36.

21. Hughes, P. M., Turton, P., Evans, C. D. H. (1999). Stillbirth as risk factor for depression and anxiety in the subsequent pregnancy: cohort study. BMJ, 378, 1721-4.

22. Beck, C.T. (2006). Postpartum depression: it isn`t just the blues. Am J Nurs, 106 (5), 40-50.

23. Özkan, S. (1993). Kadın hastalıklarl ve doğumun psikiyatrik yönleri. Psikiyatrik Tıp: Konsültasyon Lezyon Psikiyatrisi. İstanbul: ROCHE Müstahzarları Sanayi A.Ş.

24. Yılmaz, M., Öncel, S. (2009). Annelik hüznü ile baş etmede hemşirenin rolü. Türkiye Klinikleri Hemşirelik Bilimleri, 1 (1), 32-8.

25. O`Hara, M. W., McCabe, J. E.(2013). Postpartum depression: current status and future directions. The Annual Review of Clinical Psychology, 9, 379-407.

26. Brummelte, S., Galea, L. A. M. (2016). Postpartum depression: etiology, treatment and consequences for maternal care. Hormones and Behaviour, 77, 153-166.

27. Schiller, C. E., Meltzer-Brody, S., Rubinow, D. R. (2014). The role of reproductive hormones in postpartum depression. Author Manuscripts, 20 (1), 48-59.

28. Skalkidou, A., Hellgren, C., Comasco, E., Sylven, S., Paromaa, I. S. (2012). Biological aspect of postpartum depression. Women's Health, 8 (6), 659-672.

29. Beck, C. T. (2001). Predictors of postpartum depression: an update. Nurs Res, 50 (5), 275-85. 
30. Norhayati, M. N., Nick - Hazlina, N. H., Asrenee, A. R., Wan-Emilin, W. M. A. (2015). Magnitude and risk factors for postpartum symptoms: a literature review. Journal of Affective Disorders, 175, 34-52.

31. Verreault, N., Costa, D. D., Marchand, A., Ireland, K., Dritsa, M., Khalife, S. (2014). Rates and risk factors associated with depressive symptoms during pregnancy and with postpartum onset. Journal of Psychosomatic Obstetrics \& Gynecology, 35 (3), 84-91.

32. Arslantaş, H., Ergin, F., Balkaya-Akdolun, N. (2009). Aydın il merkezinde doğum sonrası depresyon sıklığı ve ilişkili risk etmenleri. AD Ü Tip Fakültesi Dergisi, 10 (3), 13-22.

33. Tahaoğlu, A. E., Toğrul, C., Külahçıŏglu, M.İ., Öztürk-Aydın, B., Balsak, D., Bademkıran, H. ve ark. (2015). Diyarbakır'da postpartum depresyonu etkileyen faktörler. Perinatoloji Dergisi, 23 (1), 26-29.

34. Erdem, Ö., Bucaktepe-Erten, P. G., Kara, İ. H. (2010). Prepartum ve postpartum dönemde annelerin depresyon ve kaygı düzeylerinin incelenmesi. Düzce Tıp Dergisi, 12 (3), 24-31.

35. Yıldırım, A., Hacıhasanoğlu, R., Karakurt, P. (2011). Postpartum depresyon ile sosyal destek arasındaki ilişki ve etkileyen faktörler. Uluslararası İnsan Bilimleri Dergisi, 8 (1), 31-48.

36. Stewart, D. E., Vigon, S. (2016). Postpartum Depression. The New England Journal of Medicine, 375 (22), 2177-86.

37. Copoglu, U. S., Kokacya, M. H., Demircan, C. (2015). Gebelik ve laktasyon döneminde ruhsal bozukluklar ve tedavisi. Mustafa Kemal Univ Derg, 6 (24), 43-53.

38. Fitelson, E., Kim, S., Baker-Scott, A., Leight, K. (2011). Treatment of postpartum depression: clinical, psychological and pharmacological options. International Journal of Women's Health, 3, 1-14.

39. Morrison, J. (2014). DSM-5`i kolaylaştıran klinisyenler için tanı rehberi. (H. UğurKural, Çev.) Ankara: Nobel Akademik Yayıncılık.

40. Essali, A., Alabed, S., Guul, A., Essali, N. (2013). Preventive interventions for postnatal psychosis. Schizophrenia Bulletin, 39 (4), 748-750

41. Fuste, M., Pauls, A., Worker, A., Reinders, A. A. T. S., Simmons, A., Williams, S. C. R., et al. (2017). Brain structure in women at risk of postpartum psychosis: an MRI study. Translational Psychiatry, 7 (1286), 1-9.

42. Bergink, V., Rasgon, N., Wisner, K.L. (2016). Postpartum psychosis: madness, mania, and melancholia in motherhood. Am J Psychiatry, 173 (12), 1179-1188.

43. Erdem, Ö., Bez, Y. (2014). Doğum sonrası psikoz. Konuralp Tip Dergisi, 6 (1), 74-77.

44. Doucet, S., Jones, I. R., Letourneau, N. L., Dennis, C. L. (2010). Interventions for the prevention and treatment of postpartum psychosis: a systematic review. Archives of Women's Mental Health, 14 (2), 89-98.

45. Chandra, P. S., Herrman, H., Fisher, J., Kastrup, M., Niaz, U., Rondon, M. B., et al. (2009). Contemporary topics in women's mental health. West Sussex: WileyBlackwell). 